\title{
The Application of Dynamic Equivalence in Translation of Ethnic Culture
}

\author{
Dr. Linli Chen \\ Associate Professor \\ School of International Exchange \\ Yunnan Open University \\ Kunming, P. R. China
}

\begin{abstract}
The translation of ethnic culture is a hard task because there are scarcely equivalents in English for the original indigenous cultures and languages of ethnic groups. It is the vocabulary and the complexity of the culture, thought, and so on that makes it difficult. It is of great importance to translate ethnic cultural concepts that reflect the characteristics and differences of ethnic groups' culture most. A reasonable option and the quality of translation are decided by the translator's cultural awareness and creativity. In this paper, translation of ethnic culture in light of dynamic equivalence will be discussed, trying to cast some enlightenment on translating ethnic cultural concepts in Chinese ethnic groups' classics and cultural phenomenon.
\end{abstract}

Keywords: Translation, ethnic culture, dynamic equivalence

\section{Dynamic Equivalence}

Eugene A. Nida put forward "dynamic equivalence" in his noted book Toward a Science of Translating published in 1964. In his opinion, "in such a translation one is not so concerned with matching the receptor language message with the source language message, but with the dynamic relationship, that the relationship between receptor and language should be substantially the same as that which existed between the original receptors and the message".(1964: 159)

In his view point, "dynamic equivalence is therefore to be defined in terms of the degree to which the receptors of the message in the receptor language respond to it insubstantially the same manner as the receptors in the source language." (Nida 2004: 24) Nida firstly introduced the term "dynamic" to the field of translation. From Nida's point of view, "Translation means translating meanings." (Nida 1993) which means the transformation of the language serves only as a kind of medium and the transformation of "meaning" really matters to translation.

The dynamic meaning is of great importance to the analysis of the translation strategies of ethnic groups' classics and cultural phenomenon. From the perspective of dynamic meanings, the language context as well as the nonlanguage context should be taken into consideration and meanings will be expressed when translating in order to achieve the desired results. The translator should take the responsibility for understanding the original, taking the social, political and cultural factors into consideration and re-expressing meanings properly. Translation cannot be absolutely separated from certain society and culture, since it is a process of transferring information from one language into another and a bilingual art of cross-cultural communication.

\section{Translation Strategies of Ethnic Culture in View of Dynamic Equivalence}

Due to language and cultural barriers, different historical backgrounds and social customs, the translation of Chinese ethnic culture has always been a very complex and hardtack for translators. The dynamic meaning holds that the meaning is not stable, closed, isolated and mechanical any more in translation studies and the translator should try to reach the dynamic equivalence of the meaning in translation. According to dynamic meanings, instead of the inner elements of language, the outer elements such as political system, cultural tradition, ideology and the original author's intention play an important role in deciding the real meaning of the source text completely, which will influence the criterion of translation and the option of translation strategies. In light of dynamic meanings, the original text is an open system of multiple and dynamic meanings which can be understood and interpreted differently according to the original author's different social, cultural backgrounds and so on. 
According to dynamic meanings, language environment is divided into two parts, they are language context including words, sentences, paragraphs and the whole text and non-language context including other outer factors such as social, cultural elements, and so on. In language context, the translator should keep his translation being in accord with the objectivity of knowledge. That is to say, the first step in translation is to get understanding of the original ethnic culture when the translator plays the role of a reader or a participant, so the translator should use his pre-knowledge to interpret the original at first.

In non-language context, the translator should keep his translation being original text-oriented which restricts the translator to the original ethnic cultural words. After having fully understood the original text, the translator is prepared to start the creative journey to reproduce what he has inferred from the original text. Ethnic culture translation is a creative activity and the translator should bear his readers in mind all the time. To be a responsible translator, he should be exposed to the related writings and materials of the original text, the author's historical background, social status, etc. as much as possible in order to share similar background knowledge and faithfully interpret the original meaning of the ethnic cultural words and cultural background. What is more, the translator should show much respect for the original and should not change the content of the original cultural words at his own will. Though the meaning is unstable and indeterminate, the translator ought to take language context and non-language context both into consideration when translating and the relatively fixed meaning will be conveyed appropriately in target language. Thus the translated ethnic cultural words will be successful and make the target language readers feel like reading the original cultural words in their own familiar culture and make them enjoy and delight in it as well.

\section{Translation Practice of Dynamic Equivalence to Ethnic Cultural words}

Equivalence translation requires equivalence of the original text and the translation in language function instead of language form. According to Nida, "translation consists in reproducing in the receptor language the closest natural equivalent of the source language message, first in terms of meaning, and secondly in terms of style."(Nida 1969: 12) The first and the most important step in translation is to understand the meanings of the words or the sentences of the original text correctly and then interpret meanings appropriately in target language. Furthermore, in order to translate satisfactory work, the translator should be familiar with the culture of source language and thus he will not misinterpret meanings. Equivalence translation requires equivalence of the original text and the translation in language function instead of language form. The following examples are translations of some Chinese ethnic cultural words and their meanings: "First Rice-seedling-transplanting Day", the first riceseedling-transplanting day is called "Ka'e'peng" in the Hani language. Hani people of Yunnan in China attach great importance to rice seedling transplanting, so they will choose an auspicious day to begin it. On this day, every household will offer sacrifices of chicken, eels, eggs and colored sticky rice to their ancestors and the patron god. In the middle of the day, they will also hold sacrificial ceremonies to worship the field god.(Song 2007: 51) It is hard to translate it appropriately if the translator is unfamiliar with the culture of Hani people.

"Spirit Worship", Hani people in Yunnan believe that a person has 12 spirits. If one or some of a person's spirits leave, he will fall ill. If he loses all his spirits, he will die. Thus, different spirit-calling ceremonies have come into being. These ceremonies are held at regular or irregular times so as to make sure that the people and their livestock are safe and healthy. (Song 2007: 54)

"God Worship", Hani people in Yunnan worship gods of nature as well as some imaginary gods like failure god, the god that paralyses people and so on. They believe that gods can either bless or harm people. Even a god will have two sides. That is why people often hold a variety of ceremonies to show their respect for the gods. The purpose is to please the gods so that they will not do harm to the people. (Song 2007: 55) It shows that equivalence translations are based on thorough understanding of ethnic culture.

"The Festival of Tasting the New Produce", also called the Harvesting Festival, is a time when the Lisu people of Yunnan celebrate their harvest. It is usually held in September or October on the Chinese Lunar Calendar when new grains and maize are gathered in. During the festival, every family tastes their new grains and their newly brewed wine. When night falls, people of all ages gather together, singing and dancing, to celebrate their harvest. (Song 2007: 120) "The Bathing Gatherings", also called "Tangquanhui", are yearly bathing gatherings held in spring among the Lisu people living in Nujiang, Yunnan. In the period from $2^{\text {nd }}$ to $6^{\text {th }}$ day of the $1^{\text {st }}$ lunar month, the Lisu people will carry with them luggage and food, and go to the hot springs called "the 16 Hot Springs in the Valley" to have a thorough bathing. 
The Lisu people believe that the hot springs here have an amazing curing effects and a bathing here can rid them of a year's pains and misfortunes. In this spring bathing period, song competitions are also held. (Song 2007: 121) Because of the accurate translation, interpret and its blessing effect, more and more people participate in the Bathing Gatherings, which makes it well known.

These examples show that a good command of Chinese cultural information is essential for translating ethnic cultural words accurately. The translator does not have to stick to the form of the source text, as long as the meaning is conveyed to the target reader, his translation is successful. And the above demonstrates that the translators all faithfully re-express meanings of the original ethnic cultural words in target language with their own understanding. It is the equivalence in both meaning and function that helps the translation of ethnic cultural words convey the meaning of the original and it will exert the same effect on the target reader as the original does upon the original reader. We should always bear in mind that whatever strategies we choose to adopt in translation, the first and the most important thing is to understand the original meaning correctly and then the meaning will be properly interpreted in target language. In the process of translation, the translator ought to have some cultural background of the target language so as to correctly and fully understand the original meaning.

The application of dynamic equivalence in translation of ethnic cultural words means that the translated text should correctly convey the literal meanings, retain the national coloring and linguistic features as much as possible. The translator should not stick to one or two methods in his translation, but try to find a most suitable method according to the context. The translator should be both bilingual and bicultural and always remember that translation is not the transferring process of language but of culture. In this way, the translation of ethnic cultural words can convey the meaning of the original in such a way that it will impose the same effect on the target reader as the original does upon the original reader.

\section{Ethnic Culture and Translation}

Culture is changeable and adaptable. Cultural communication can promote the development of various countries. However, the use of different languages blocks the exchange of different cultures. It has been commonly accepted that translation involves both language and culture. Translation deals not only with turning the content in one language into another but also with turning the cultural connotation into another cultural form. Eugene A. Nida once pointed out: "For a truly successful translating, biculturalism is even more important than bilingualism, since words only have meanings in terms of the cultures in which they function." (Nida 2002: 82) Actually, Nida's theory can be applied as a guiding criterion in all kinds of translation, and the translation of ethnic cultural words is not an exception.

Every country has its own ethnic groups, geographical location, religious beliefs, values, political systems and so on. All these form the differences of national culture, which are also certainly embodied in language. Cultures of various countries have something similar or in common. All these similarities and generalities are inevitably embodied in languages. The influence of culture on language brings difficulties to translating. Neglect of these cultural differences often leads to errors. As language is a tool for cultural dissemination and communication, translation is a bridge and an essential means of cultural understanding and exchange. Studies on the relationship of ethnic culture and translation will give an impetus to cultural communication to the promotion of the prosperity of cultures in different countries and different nations, to the enrichment of the global culture and acceleration of the development of the world civilization.

\section{Conclusion}

Nida put forward "dynamic equivalence" to emphasize the dynamic equivalence of meanings. The dynamic meaning has exerted strong influence upon translation studies. It holds that since the meaning is unstable and dynamic the translator should play a dynamic role in understanding and interpreting the original meaning correctly and properly both from language context and non-language context so as to reach the dynamic equivalence of meanings in translation. To speak concretely, the meaning seized from the original text and produced in the translated text is the result of translator's specific interaction with the original text. In translation, the translator should fully reflect the messages and notions of the original ethnic culture based on his own preexisted ideology and pre-knowledge of the culture information in the target language so as to make the translated works more readable and acceptable. Furthermore, as an active and dynamic part in translation, the translator should also have his own translation purpose and intended readers on which his translation strategies and approaches will decide. 
Translation is a complex process of language and culture transferring. Due to the different translation circumstances and target readers, different translation strategies should be adopted. This paper is only a preliminary research on the translation of ethnic culture in the perspective of dynamic equivalence with cultural considerations. It is believed that further research on its translation and more explorations on its connotations in different ethnic groups' cultural contexts are still necessary.

\section{Acknowledgment}

This work was supported by National Social Science Foundation of China.

\section{References}

Goodman J. The Exploration of Yunnan. Kunming: Yunnan People's Publishing House.

Linli Chen. (2010). On Integrated Translation Approach of English Idioms. Journal of Language Teaching and Research, Vol. 1, No 3, May 2010.

Linli Chen. (2009). On Literal Translation of English Idioms. English Language Teaching, Vol.2, No.2 June 2009.

Liying Song. (2007). Indigenous Ethnic Groups in Yunnan. Kunming: Yunnan University Press.

Newmark, P.P. (1982). Approaches to Translation. Pergamon. Oxford.

Nida, Eugene. A. (1964). Towards a Science of Translating. Brill. Leiden.

Nida, Eugene. A. (1993). Language, Culture, and Translating. Shanghai: ShanghaiForeign Language Education Press.

Nida, Eugene.A. (2002).Language and Culture: Contexts in Translating. Shanghai: Shanghai Foreign Language Education Press.

Nida, Eugene. A. (1986).From one Language to Another. Shanghai: Shanghai Foreign Language Education Press. 